\title{
ARTIFICIAL NEURAL NETWORK MODEL FOR MANAGING AND FORECASTING WATER RESERVOIR DISCHARGE (HEMREN RESERVOIR AS A CASE STUDY)
}

\author{
ABBAS M. ABD ${ }^{1}$, SAAD SH. SAMMEN ${ }^{2}$ \\ ${ }^{1}$ Assistant Professor, ${ }^{2}$ Lecturer \\ ${ }^{1,2}$ College of Engineering, Diyala University \\ (Received: 6/10/2013; Accepted: 22/9/2014)
}

\begin{abstract}
The prediction of different hydrological phenomenon (or system) plays an increasing role in the management of water resources. As engineers; it is required to predict the component of natural reservoirs' inflow for numerous purposes. Resulting prediction techniques vary with the potential purpose, characteristics, and documented data. The best prediction method is of interest of experts to overcome the uncertainty, because the most hydrological parameters are subjected to the uncertainty. Artificial Neural Network (ANN) approach has adopted in this paper to predict Hemren reservoir inflow. Available data including monthly discharge supplied from DerbendiKhan reservoir and rain fall intensity falling on the intermediate catchment area between Hemren-DerbendiKhan dams were used.

A Back Propagation (LMBP) algorithm (Levenberg-Marquardt) has been utilized to construct the ANN models. For the developed ANN model, different networks with different numbers of neurons and layers were evaluated. A total of 24 years of historical data for interval from 1980 to 2004 were used to train and test the networks. The optimum ANN network with 3 inputs, 40 neurons in both two hidden layers and one output was selected. Mean Squared Error (MSE) and the Correlation Coefficient (CC) were employed to evaluate the accuracy of the proposed model. The network was trained and converged at MSE $=0.027$ by using training data subjected to early stopping approach. The network could forecast the testing data set with the accuracy of MSE $=0.031$. Training and testing process showed the correlation coefficient of 0.97 and 0.77 respectively and this is refer to a high precision of that prediction technique.
\end{abstract}

Key words: ANN model, Forecasting, artificial neural network, reservoir inflow 


\section{INTRODUCTION}

The reservoir inflow prediction is extremely important for the management of a water resources system; it could be by hours, days, months or possibly longer in advance. Water boards, with a reliable prediction of reservoir inflow, can optimally allocate water supplies for competing users e.g., agricultural, domestic, hydropower generation, and for environmental purposes. In the case of multipurpose reservoirs, the reservoir inflow prediction is particularly important for the flood mitigation reservoir's systems, and it is indispensable. Also this prediction provides information about the sedimentations carried by the river to the reservoirs.

In the last few decades, time series forecasting has received a supreme attention of researchers. This was due to the importance for planning using the future values of the physical variable, which measured in discrete or continuous time basis; also it is important for design and management activities. This prediction method had been applied and introduced in very wide areas such as: computer science, finance and business, physics, chemistry and many interdisciplinary fields, all branches of engineering, medicine.

Traditionally, many researchers have employed traditional methods of time series analysis, modeling, and forecasting, e.g. Box-Jenkins methods of autoregressive (AR), autoregressive moving average (ARMA), auto-regressive integrated moving average (ARIMA), autoregressive moving average with exogenous inputs (ARMAX), etc. The conventional time series modeling methods have served the scientific community for a long time; however, they provide only reasonable accuracy and suffer from the assumptions of stationary and linearity. The need of producing more and more accurate time series forecasts has forced the researchers to develop innovative methods to model time series.

Artificial Intelligent; especially Neural Networks (ANNs) were adopted as efficient tools for modeling and prediction purposes. Artificial neural networks (ANNs) have verified as efficient prediction method and for modeling qualitative and quantitative water resource variables (Maier and Dandy 1996; Olsson et al. 2004). Also, the artificial neural networks are techniques that can model, map, and demonstrate the nonlinear relationship of complex phenomena. The artificial neural networks are universal and highly flexible function approximates, first used in the fields of cognitive science and engineering (Kaastra and Boyd, 1996). The neural networks are less sensitive to the error term assumptions and can tolerate noise, chaotic components, and heavy tails better than most other methods (Masters, 1993).This work is aimed to presents forecasting a hydrologic time series using neural network approaches. 


\section{HYDROLOGICAL FORECASTING USING ANN}

Artificial Neural Network (ANN) firstly introduced by McCulloch and Pitts (Mcculloch 1943). But, it was mostly dormant until the mid-1980s. The utilization of ANN witnessed dramatically and rapid evolution until became very popular in recent years.

ANN application in hydrology started in the early 1990s. The ASCE task committee report was the state-of-the-art review of ANN applications in hydrology. Some of ANN applications in water resources cover:

- Precipitation-runoff modeling (Wu and Chau 2011)

- Stream flow forecasting (Moradkhani et al., 2004; Anctil et al., 2004),

Also, many attempts have been made to develop runoff hydrographs using different parameters as inputs such as:

- Investigation of the performance of the ANN trained with back-propagation algorithm for 1-week-ahead stream flow forecasting (Zealand et al., 1999).

- Developing the ANN to simulate unit hydrograph, and the weighting matrix was taken as a unit hydrograph after training by ANN (Hjelmfelt et al., 1993).

- Constructing a counter-propagation fuzzy-neural network model to approach the real time stream flow estimation (Chang and Chen, 2001).

- Using the cascade correlation and back-propagation algorithms in hourly river flow prediction by Imrie et al. (Tokar 2000).

- Kisi in 2004, explained the application of ANNs with standard back-propagation algorithm for predicting monthly mean stream flow.

- Antar et al. (2006) used ANN models with back-propagation algorithm in daily runoff estimation.

- Huang et al. in 2004, used back-propagation and conjugate gradient algorithm for shortand long-term flow forecasting.

- Many researchers adopt ANN to predict a models for different area in civil engineering as S.M. et al 2006, A.M. et. al. 2008 (a \& b), 2012 and 2014, A. Ismail 2008 and 2009.

\section{ANN STRUCTURE}

The ANN initial properties are the ability to learn, organize memory and consequent operation, eventually reaching the fault tolerance. A typical three-layered network with an input layer (I), a hidden layer $(\mathrm{H})$ and an output layer $(\mathrm{O})$, as shown in Figure (1), is adopted in this study. 
It's known that the increasing of the hidden layers number affects the complexity of the network and decreases the learning accuracy. Theoretical works have shown that a single hidden layer is sufficient for the ANNs to approximate to any complex nonlinear function (Cybenko, 1989).Meanwhile in 1999; Michael et al. recommended using one hidden layer to avoid increasing the complexity of the network. Indeed, many experimental results seem to confirm that one hidden layer may be enough for most forecasting problems (Coulibaly et al., 1999).Each layer includes several neurons and the layers are interconnected by sets of correlation weights. The neurons produce outputs through transforming inputs comes from the initial inputs or the interconnections, by an adequate nonlinear transfer function. Sigmoid function is the common transfer function which is the expressed by

$$
f(x)=\frac{1}{1+e^{-x}}
$$

Commonly, this function used in back propagation networks (BPN). The training processing of neural network is essentially executed through a series of patterns, and for the learning process, the interconnection weights are adjusted within input and output values. The back propagation is the most representative learning model for the artificial neural network.

In the back propagation procedure, the error at the output layer propagates backward to the input layer via the hidden layer in the network obtaining the final optimum outputs. The gradient descent method is adopted to find the weight of the network and calibrate the weight of interconnections to minimize the output error. According to Frederic (2001), the error function, for (n) hidden layers network, at the output neuron can be defined as:

$$
E_{q}(w)=\frac{1}{2}\left(d q-x_{\text {out }}^{(n+1)}\right)^{T}\left(d q-x_{\text {out }}^{(n+1)}\right)=\frac{1}{2} \sum\left(d q-x_{\text {out }}^{(n+1)}\right)^{2}
$$

Where $\mathrm{d}_{\mathrm{q}}$ represents the desired network output for the $\mathrm{q}^{\text {th }}$ input pattern and $X_{\text {out }}{ }^{(n+1)}$ is the actual output of the network. Using the steepest descent gradient approach, the learning rule for a network weight in any one of the network layers depends on the learning rate.

\section{LEVENBERG-MARQUARDT BACK PROPAGATION ALGORITHM}

The ANN-based modeling was reviewed in the hydrology over the last years by Coulibaly et al. (1999) and reported that about $90 \%$ of the experiments, extensively make use of the multi-layer feed-forward neural networks (FNN) trained by the back propagation algorithm. Early stop training approach Levenberg-Marquardt back propagation (LMBP) algorithm has widely been used for the hydrological forecasting problems, as the most powerful and accurate algorithm (Cobaner et al., 2008; Vongkunghae and Chumthong, 2007). 
The Levenberg- Marquardt algorithm represents a simplified model of Newton's method applied to the problem of training multilayer perceptron neural networks.

The Correlation Coefficient (CC) and Mean Square Root Error (MSE) are the most commonly used statistics to evaluate the ANN models performance (Stephen et al., 2007).Thus, to estimate the accuracy of the proposed methodology, the Mean Squared Error (MSE) and Correlation Coefficient (CC) were used as the agreement indexes:

$$
\begin{aligned}
& M S E=\sum_{k=1}^{n} \frac{\left(y_{k}-\jmath_{k}\right)^{2}}{n^{2}} \\
& C C=\frac{\sum_{k=1}^{n}\left(y_{k}-\bar{y}_{k}\right)\left(\jmath_{k}-\bar{\jmath}_{k}\right)}{\sqrt{\sum_{k=1}^{n}\left(y_{k}-\bar{y}_{k}\right)^{2} \sum_{k=1}^{n}\left(\jmath_{k}-\bar{\jmath}_{k}\right)^{2}}}
\end{aligned}
$$

Where $z_{k}$ is the observed value, $y_{k}$ is the predicted value, is $\bar{y}_{k}$ the mean value of observations, and $\bar{\jmath}_{k}$ is the mean value of predictions.

The most important part of ANN model is its ability to forecast future events. The MSE and $\mathrm{CC}$ criterions are employed for evaluation of the accuracy of training procedure. The best model is chosen according to the minimum MSE and the Maximum CC.

\section{RESULTS AND DISCUSSION}

ANN models were developed through calculating the effect of three parameters; average of monthly rain, discharge from Khanakin dam, and the inflow to Hemren reservoir. Historical data of 24 years (1980 to 2003) was adopted in this work, Table (1) shows sample of the results for one month using the ANN model to predict the average inflow.

It is obvious through the column 5 (difference rate) that most of the results have high degree of divergence, i.e. the difference rate was 0.001 to 1.19 . This reflect high reliability of the model.

The evaluation process of the model was made using the statistic performance indicators: Mean Square Error (MSE) and Correlation Coefficient (R). Table (2) list the correlation coefficient for each month, it was 0.65 for Jun to 0.95 for January.

A Back Propagation (LMBP) algorithm (Levenberg-Marquardt) has been utilized to construct the ANN models. For the developed ANN model, different networks with different numbers of neurons and layers were evaluated. Meanwhile a total of 24 years of historical data for interval from 1980 to 2003 were used to train and test the networks. The optimum ANN network was with 3 input layers of 40 neurons in each layer. The network was trained and converged at MSE $=0.027$ by using training data subjected to early stopping approach. The network could forecast the testing data set with the accuracy of MSE $=0.031$. Training 
and testing process showed the overall correlation coefficient of 0.9728 and 0.7665 respectively.

Figure (2) show the behavior of the overall model for the period of historical data since 1980 to 2003 . The model was very close in most point to the actual set of data. Meanwhile, the difference indicator line was moved on the zero axes in most time.

Figure (3) and (4) show the monthly behavour of the predicted model with the actual data and it reflect the effect of rain for the rain season for the interval from October to June on the model.

\section{CONCLUSIONS}

An artificial feed-forward neural network model (newff) with Back Propagation (LMBP) algorithm (Levenberg-Marquardt) is adopted to predict the monthly flow discharge in the Hemren reservoir by learning and recalling process.

Results show the neural network provides a high accuracy prediction of flow discharge for the future in Hemren reservoir depended on Derbendi-Khan reservoir outflow and the rainfall in catchment area between Derbendi-Khan and Hemren reservoirs for overall period from 1980 to 2003 as shown in figure (2) and for each month as shown in Figures (3 \& 4) . The optimum ANN network with 3 input layers, 40 neurons in each layers and one output layer was selected as the best model. Mean Squared Error (MSE) and the Correlation Coefficient (CC) were employed to evaluate the accuracy of the proposed model. The network was trained and converged at MSE $=0.027$ by using training data subjected to early stopping approach. The network could forecast the testing data set with the accuracy of MSE $=0.031$. Training and testing process showed the correlation coefficient of 0.9728 and 0.7665 respectively. Also, the model was of good reliability in term of results according to how much data is available for training the network. Finally, this work prove that this model can be used as a considerable predicting tool for the inflow for Hemren reservoir.

\section{REFERENCES}

1- Anctil F., Claude M., Charles P., Vazken A. (2004). A soil moisture index as an auxiliary ANN input for stream flow forecasting. J. Hydrol., 286: 155-167.

2- Antar, M. A., Elassiouti, I., and Allam, M. N. (2006). "Rainfall-runoff modelling using artificial neural networks technique: A Blue Nile catchment case study" Hydrolog. Process, 20(5), 1201-1216. 
3- Chang, F.-J., Chen, Y.-C., 2001. A counter propagation fuzzy-neural network modeling approach to real time streamflow prediction. Journal of Hydrology, 245 (1-4), 153-164.

4- Cobaner M, Information C, Haktanir T, Kisi O (2008). Prediction of Hydropower Energy Using ANN for the Feasibility of Hydropower Plant Installation to an Existing Irrigation Dam. Water Resour. Manage, 22: 757-774.

5- Coulibaly P, Anctil F. Bobée B. (1999). Prévision hydrologique parréseaux de neurones artificiels : état de l'art. Can. J. Civ. Eng., 26 (3): 293-304.

6- Cybenko G (1989) Approximation by superpositions of a sigmoidal function. Math. Ctrl. Signals Syst. (MCSS), 2: 303-314.

7- Frederic MH (2001). Principles of neurocomputing for science and engineering. McGraw Hill. New York.

8- Hjelmfelt, A.T., Wang, M. 1993. Runoff simulation using artificil neural networks, Proceedings twenty-fifth Congress of the International Association for Hydraulic Research. Special Lectures, Technical Session A, Flood and Drought, 1, 517-522.

9- Huang, W., Xu, B., and Hilton, A. C. (2004). "Forecasting flows in Apalachicola River using neural networks." Hydrolog. Process, 18_13_, 2545-2564.

10- Kaastra I, Boyd M (1996). Designing a neural network for forecasting financial and economic time series. Neurocomputing, 10: 215-236.

11- Kisi, O. (2004). "River flow modeling using artificial neural networks.” J. Hydrol. Eng., 9 (1), 60-63.

12- Maier, H. R., and Dandy, G. C. (1996). "Use of artificial neural networks for prediction of water quality parameters.” Water Resour. Res., 32(4), 1013-1022.

13- Masters T (1993). Practical Neural Network Recipes in C++. Academic Press. Boston.

14- Mcculloch, W. S., and Pitts, W., 1943. A Logical Calculus of the Ideas Immanent in Nervous Activity. Bulletin of Mathematical Biophysics 5: pp.115-133.

15- Moradkhani H, Hoshin KL. H., Gupta V, Sorooshian S (2004). Improved stream flow forecasting using self-organizing radial basis function artificial neural networks. J. Hydrol., 295: 246-262.

16-Olsson, J., et al. (2004). "Neural networks for rainfall forecasting by atmospheric downscaling.” J. Hydrol. Eng., 9(1), 1-12.

17- Wu, C.L., K.W. Chau. "Rainfall-runoff modeling using artificial neural network coupled with singular spectrum analysis. Journal of Hydrology. V.399 (3-4): 394-409, 2011.

18-Stephen AB, Hua-Liang W, Michael AB (2007). Generalized multiscale radial basis function networks. Neu. Netw, 20: 1081-1094. 
19- Michael Nelson, Tim Hill, William Remus, Marcus O'Connor. “Time series forecasting using neural networks. Journal of Forecasting, V.18 (5): 359-367, 1999.

20- Tokar AS, Markus M (2000). Precipitation-runoff modeling using artificial neural networks and conceptual models. J. Hydrol. Eng., 5: 156-161.

21-Vongkunghae A, Chumthong A (2007). The performance comparisons of backpropagation algorithm's family on a set of logical functions. Trans. Electrical Eng., Electron. Commun., 5: 114-118.

22-Zealand CM, Burn DH, Simonovic SP (1999). Short term stream flow forecasting using artificial neural networks. J. Hydrol., 214: 32-48.

23- A. Ismail, AM Abd, Z Chik, MFM Zain. 2009. Performance assessment modelling for the integrated management system in construction projects. European Journal for Scientific Research 29 (2), 269-280.

24- A. Ismail, AM Abd, ZB Chik. 2008. Approach to Analyze Risk Factors for Construction Projects Utilizing Fuzzy Logic. Journal of Applied Sciences 8 (20).

25- AM Abd, SM Abd, A. Ismail, MFM Zain. 2008. Utilization of Value Engineering to Optimize Concreting Productivity. Journal of Applied Sciences 8 (19).

26- Abbas M. Abd,Amiruddin Ismail, Zamri Bin chik, and Suhad M. Abd. 2008. Multi neurofuzzy modelling system to simulate the effect of risk and quality requirement on the construction project performance. Proc. of national seminar on fuzzy theory and applications, Fuzzy From Theory to Applications, pp: 1-10.

27- Abbas M. Abd, Suhad M. Abd. 2014. Neuro-fuzzy model to evaluate ready-mix concrete properties. Int. J. Engg. Res. \& Sci. \& Tech (IJERST).Vol. 3, No. 1.pp 24-33.

28- Abbas M. Abd, Suhad M Abd. 2012. Resources sustainability planning model using hierarchical approach for construction project. (DJES) Diyala journal of Engineering Sciences. Vol. 05, No. 02, pp. 1-19.

29-SM Abd, AM Abd, MF.M Zain, A. Ismail. 2006. Development of productivity assessment methodology for concreting process ARPN Journal of Engineering and Applied Sciences. Vol.3 (5), pp.: 1-7.

Table 1: The predicted inflow using ANN model for January.

\begin{tabular}{|c|c|c|c|c|c|c|}
\hline Jan. & Rain & Disch & Inflow & Predicted & Diff & Diff. rate \% \\
\hline 1980 & 24.0 & 147.0 & 240.0 & 233.1 & -6.9 & -0.03 \\
\hline 1981 & 13.0 & 102.0 & 188.0 & 148.3 & -39.7 & -0.27 \\
\hline 1982 & 17.5 & 158.0 & 193.0 & 123.6 & -69.4 & -0.56 \\
\hline 1983 & 5.8 & 90.0 & 90.0 & 90.6 & 0.6 & 0.01 \\
\hline
\end{tabular}


ARTIFICIAL NEURAL NETWORK MODEL FOR MANAGING AND FORECASTING WATER RESERVOIR DISCHARGE (HEMREN RESERVOIR AS A CASE STUDY)

\begin{tabular}{|c|c|c|c|c|c|c|}
\hline 1984 & 26.0 & 260.0 & 327.0 & 328.5 & 1.5 & 0.00 \\
\hline 1985 & 8.4 & 143.0 & 150.0 & 138.7 & -11.3 & -0.08 \\
\hline 1986 & 14.1 & 150.0 & 146.0 & 163.0 & 17.0 & 0.10 \\
\hline 1987 & 7.6 & 281.0 & 369.0 & 390.1 & 21.1 & 0.05 \\
\hline 1988 & 3.3 & 110.0 & 118.0 & 103.1 & -14.9 & -0.14 \\
\hline 1989 & 13.1 & 119.0 & 138.0 & 154.4 & 16.4 & 0.11 \\
\hline 1990 & 0.0 & 90.0 & 111.0 & 49.3 & -61.7 & -1.25 \\
\hline 1991 & 11.0 & 182.0 & 209.0 & 201.5 & -7.5 & -0.04 \\
\hline 1992 & 15.8 & 106.0 & 184.0 & 138.0 & -46.0 & -0.33 \\
\hline 1993 & 23.3 & 362.0 & 466.0 & 614.5 & 148.5 & 0.24 \\
\hline 1994 & 2.5 & 273.0 & 345.0 & 324.5 & -20.5 & -0.06 \\
\hline 1995 & 33.8 & 122.0 & 217.0 & 188.1 & -28.9 & -0.15 \\
\hline 1996 & 20.1 & 117.0 & 161.0 & 180.5 & 19.5 & 0.11 \\
\hline 1997 & 40.1 & 140.0 & 270.0 & 275.3 & 5.3 & 0.02 \\
\hline 1998 & 31.3 & 35.0 & 120.0 & 124.6 & 4.6 & 0.04 \\
\hline 1999 & 13.3 & 33.0 & 65.0 & 69.4 & 4.4 & 0.06 \\
\hline 2000 & 11.2 & 28.0 & 77.0 & 36.6 & -40.4 & -1.11 \\
\hline 2001 & 35.3 & 28.0 & 132.0 & 134.5 & 2.5 & 0.02 \\
\hline 2002 & 0.0 & 127.0 & 185.0 & 84.6 & -100.4 & -1.19 \\
\hline 2003 & 29.9 & 118.0 & 225.0 & 160.0 & -65.0 & -0.41 \\
\hline
\end{tabular}

Table 2: Correlation coefficient for the monthly inflow predicted values.

\begin{tabular}{|c|c|c|c|c|c|}
\hline Oct: 0.73 & Nov: 0.83 & Des: 0.78 & Jan: 0.95 & Feb: 0.89 & Mar: 0.88 \\
\hline Apr: 0.86 & May: 0.80 & Jun: 0.65 & Jul: 0.89 & Aug:0.89 & Sep: 0.77 \\
\hline
\end{tabular}

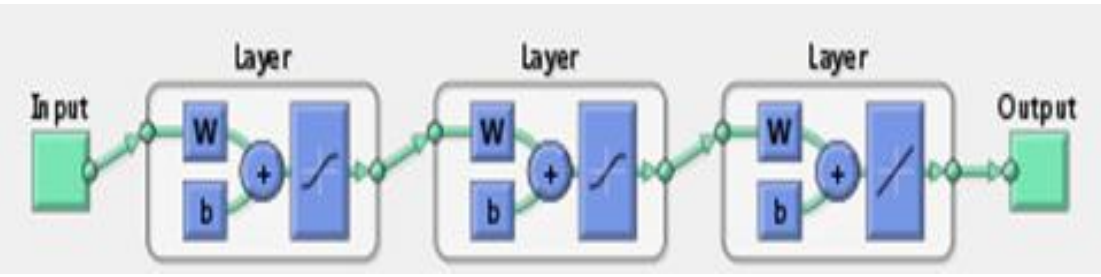

Figure (1): Structure of an artificial neural network.

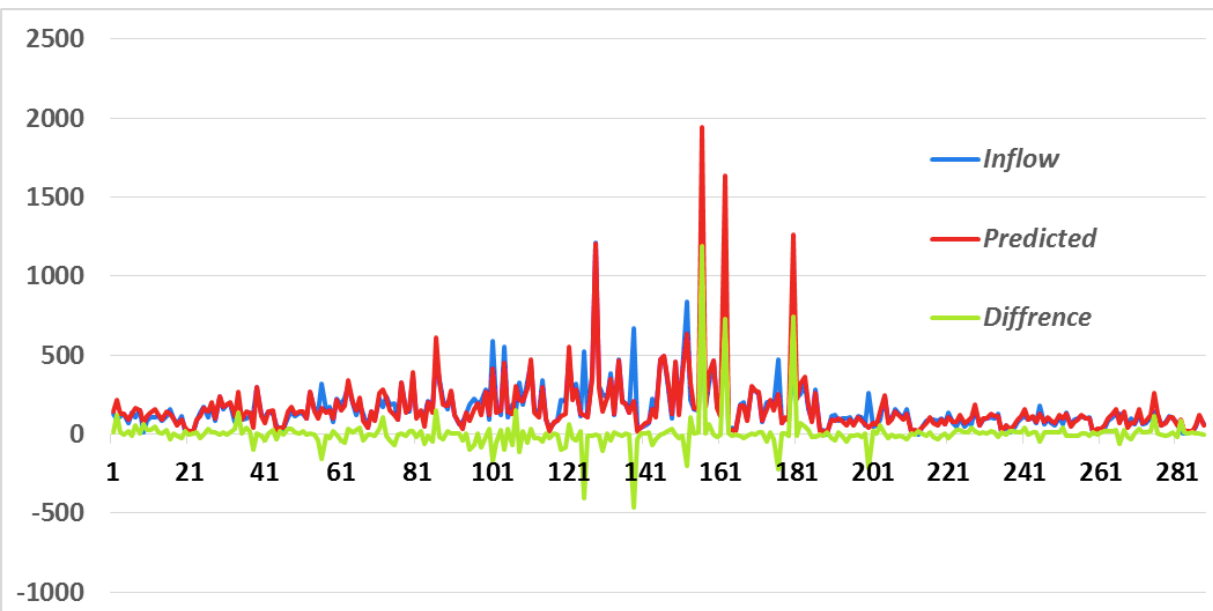

Figure (2): Real and Predicated inflow in Hemren reservoir for period 1980 -2004. 


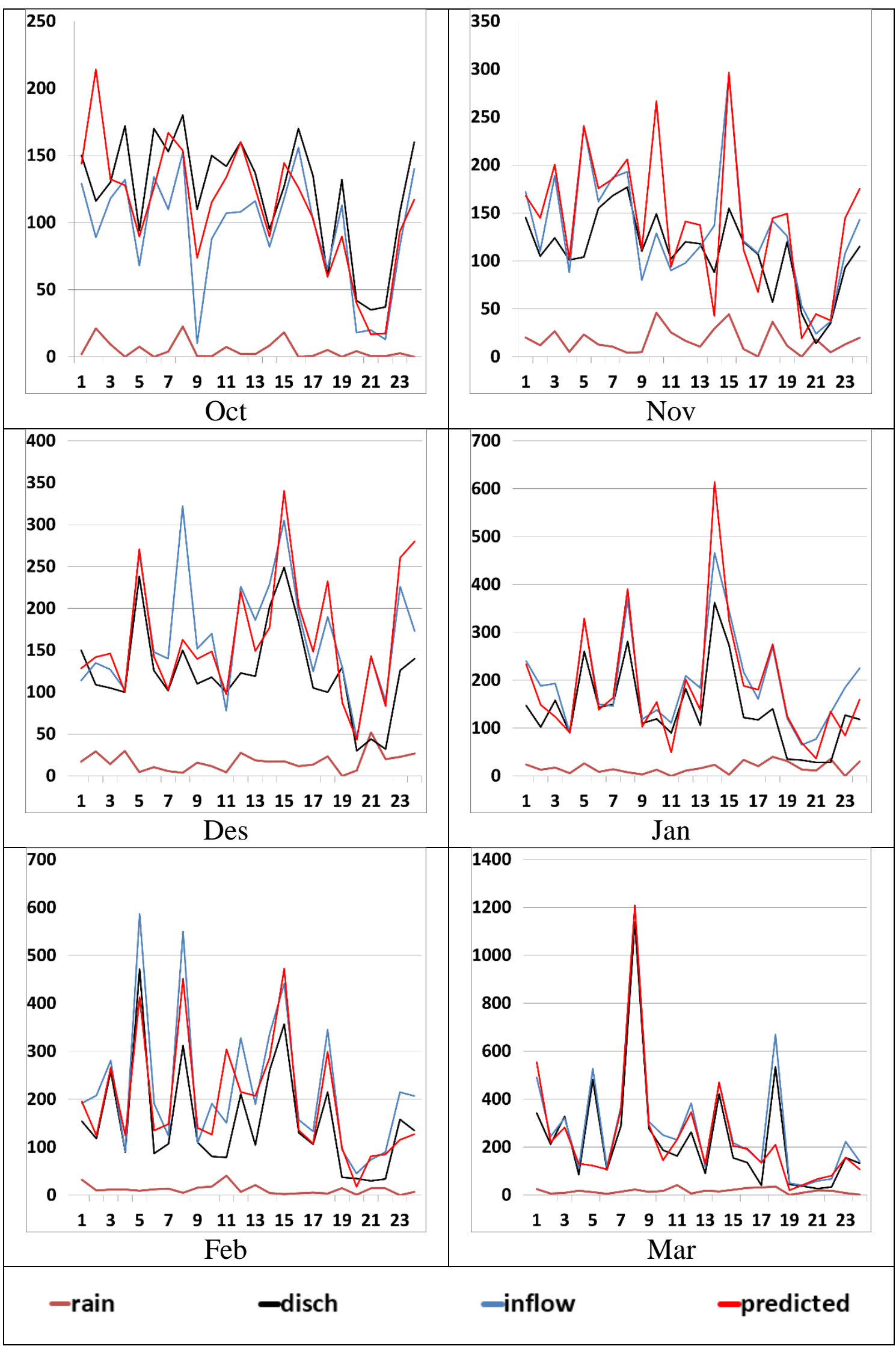

Figure (3): Real and Predicated inflow in Hemren reservoir for (Oct. to Mar.) 


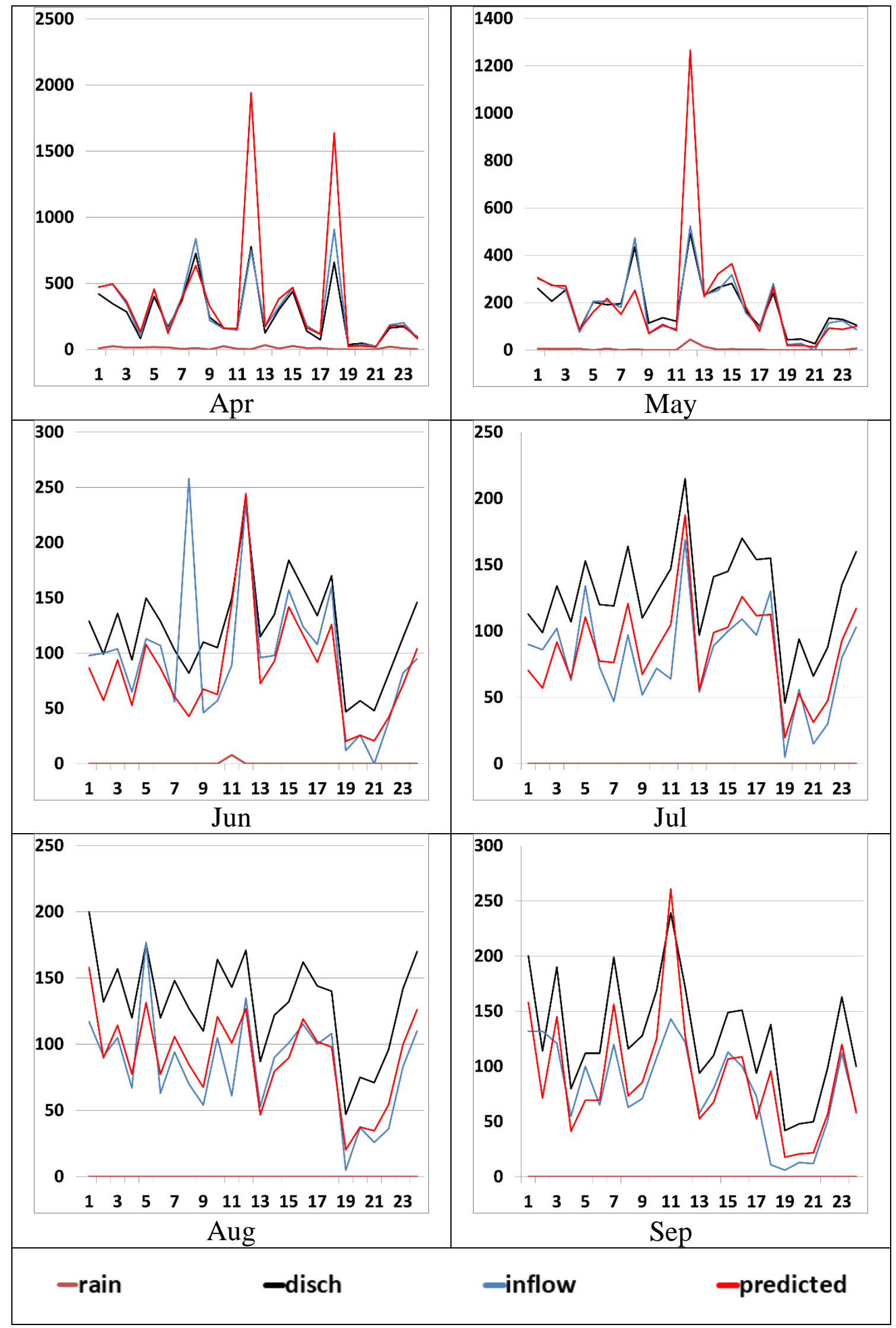

Figure (4): Real and Predicated inflow in Hemren reservoir for (Apr. to Sep.). 


\title{
اعتماد نموذج الشبكات العصبية لغرض الادارة والتنبؤ بتصريف الخزانات المائية: خزان حمرين كحالة دراسية
}

\author{
عباس مهذي عبد 1، سعد شوكت سمين 2

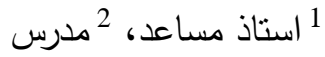

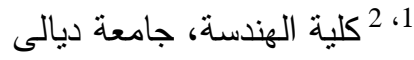

يشهد استخدام تقنيات التنبؤ اهمية متعاظمة في مجال ادارة الموارد المائية. ومن الناحية الهندسية فان عملية التتبؤ بالمصادر المائية للخزانات يكتسب اهمية كبيرة. وتتتوع طرق التتبؤ وفقا للاغراض المستهدفة والخصائص والبيانات المتوافرة. وافضل الطرق هي ما يبنى على الخبرات المتميزة ويراعي التغاير وعدم الموثوقية كونها من صفات الظاهر

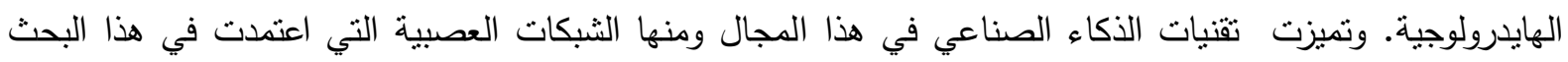
لدراسة خزان حمرين باعتماد البيانات المتوافرة لكميات الامطار والتريف المطلق من سد دربندخاء لهان.

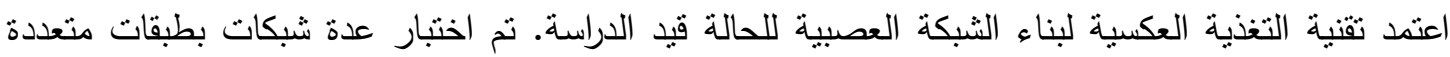
وذات عدد نيورون مختلف للوصول للحالة الامتل في بناء النموذج المثنل للحالة الدراسية. استخدمت في هذا البحث بيانات السنوات 1980-2003 لتدريب الثبكة العصبية واختبارها. تم استخدام معدل مربع الخطأ لتدقيق ناتج النموذج المطور كما نم اعتماد معامل الارتباط للتحقق من دقة النتائج. اظهرت عملية التحليل ان معدل مربع الخطأ كان بحدود 0.031 ومعامل الارتباط للنموذج على بيانات السنوات الاربع والعشرين بحدود 0.9728 وللبيانات المحدد للنحقق بحدود 0.7665 وهي درجة جيدة لدقة النموذج. 